\title{
Main causes of death among Swedish women born 1914 and 1918: 32-year follow-up of the Population Study of Women in Gothenburg
}

This article was published in the following Dove Press journal:

International Journal of General Medicine

II July 2012

Number of times this article has been viewed

\author{
Dominique Hange \\ Jóhann Ag Sigurdsson ${ }^{2}$ \\ Cecilia Björkelund' \\ Leif Lapidus ${ }^{3}$ \\ Calle Bengtsson' \\ 'Department of Public Health and \\ Community Medicine/Primary \\ Health Care, the Sahlgrenska \\ Academy, University of Gothenburg. \\ Gothenburg, Sweden; ${ }^{2}$ Department \\ of Family Medicine, University of \\ Iceland and Centre of Development, \\ Primary Health Care of the Capital \\ Area, Reykjavík, Iceland; Institute \\ of Medicine, the Sahlgrenska \\ Academy, University of Gothenburg, \\ Gothenburg, Sweden
}

Background: Coronary heart disease has been reported to be the major cause of death of postmenopausal women in industrialized countries. The risk for women of dying from myocardial infarction is significantly greater than the risk of dying from cancer. The aim of this study was to compare previous observations regarding causes of death with the results from the Population Study of Women in Gothenburg. We also examined how causes of deaths vary among different age cohorts.

Methods: This follow-up report based on the prospective observational Population Study of Women in Gothenburg, Sweden was confined to mortality in two age cohorts: 180 women born in 1914 and 398 women born in 1918. These women were representative of the female population in Gothenburg in these age groups. Women were followed for 32 years, from 1968-1969 to 2000-2001. During the follow-up period, data on mortality were obtained from the population registry and the Cause of Death Register. Women's death certificates were also examined.

Results: In women aged between 60 and 80 years, cancer accounted for $30 \%$ of deaths, myocardial infarction for $19 \%$, and stroke for $14 \%$. In women who died after the age of 80 years, myocardial infarction was a more common cause of death than cancer.

Conclusions: Cancer accounts for most years lost from a woman's normal life span. Myocardial infarction was a more common cause of death than cancer only in women above the age of 80 years. Although myocardial infarction is a common cause of death among women, cancer is a more common cause of death at younger ages. This should be emphasized when planning care, prevention, and research involving women's health.

Keywords: causes of death, mortality, population study, women

\section{Introduction}

The press and television occasionally report that women with acute coronary syndromes, such as myocardial infarction, receive more latent treatment than do men with the same diagnosis. ${ }^{1}$ This may be because women experience more unrecognized myocardial infarctions compared to men. ${ }^{2}$ It has been reported that coronary heart disease is the primary cause of death of postmenopausal women in industrialized countries, ${ }^{3}$ and that the risk of women dying from myocardial infarction is significantly greater than the risk of dying from cancer. ${ }^{4-7}$

Causes of death and mortality have been studied in many countries. The life expectancy both in men and women in the US increased until 1983. However, between 1983 and 1999, female mortality increased in the US, primarily due to chronic diseases related to smoking, obesity, and blood pressure. ${ }^{8}$
Correspondence: Dominique Hange Department of Public Health and Community Medicine/Primary Health Care, PO Box 454, SE-405 30 Göteborg, Sweden

Tel +46317736843

Fax +46317781704

Email dominique.hange@vgregion.se 
Recently, the life expectancy of women has increased, and 2006 was the first year in which women worldwide were reported to have a longer life expectancy than men. ${ }^{9}$ In 2004, the World Health Organization presented estimates of different causes of death on global, regional, and country levels and provided an overview of global and regional patterns. In 111 countries, ischemic heart disease and cerebrovascular disease were the leading causes of death. ${ }^{10}$

Previous studies have shown that the leading causes of death in 1990 were ischemic heart disease (6.3 million deaths) and cerebrovascular diseases (4.4 million deaths), whereas lung cancer caused 0.9 million deaths. ${ }^{11}$

The aim of this study was to compare previous observations regarding mortality and causes of death in women with the results of the Population Study of Women in Gothenburg. The Population Study of Women in Gothenburg recorded data regarding both mortality and morbidity for more than 40 years.

\section{Participants and methods}

The Prospective Population Study of Women in Gothenburg was initiated in 1968-1969. ${ }^{12}$ Women participated in a comprehensive health assessment, and selection was based on date of birth to ensure that the women were representative of all women in Gothenburg in the age groups studied. The high participation rate, which was approximately $90 \%$, further supported the hypothesis that this population was representative of the general population.

This follow-up report was conducted to examine mortality in two age cohorts. A total of 398 women born in 1918 who were 50 years old at baseline were followed from 32 years to 82 years of age, with the study period ending in 2000. Additionally, 180 women born in 1914, who were 54 years old at baseline and 86 years old in 2000, were also followed. The number of participants, participant rates in 1968-1969, and the number of deaths are shown in Table 1.

\section{Definition of myocardial infarction, other cardiovascular diseases, and stroke}

A woman was defined as having myocardial infarction, heart failure, other cardiovascular diseases, or stroke if a diagnosis had been made by a doctor and classified according to the International Classification of Diseases, ${ }^{13}$ Ninth and Tenth Revision (ICD 9 and 10), diagnosis codes ICD 391-448B or I01.0-I79.2, respectively (myocardial infarction, heart failure, other cardiovascular diseases, and stroke). Data from
Table I Year of birth, number of participants, and participant rate for the two different age groups examined in the Population Study of Women in Gothenburg 1968-1969 and the number of deaths over the 32-year study period (2000-200I)

\begin{tabular}{lllllll}
\hline $\begin{array}{l}\text { Year of } \\
\text { birth }\end{array}$ & $\begin{array}{l}\text { Age in } \\
\text { 1968-1969 }\end{array}$ & \multicolumn{2}{c}{ Participants } & & \multicolumn{2}{c}{ Mortality in 32 years } \\
& & $\mathbf{n}$ & $\%$ & & $\mathbf{n}$ & $\%$ \\
\hline 1918 & 50 & 398 & 91.0 & & 166 & 41.7 \\
1914 & 54 & 180 & 88.6 & & 115 & 63.9 \\
\hline
\end{tabular}

Abbreviation: $\mathrm{n}$, number of participants.

between 1980 and 2001 were obtained from the Swedish Hospital Register.

\section{Verification of cancer diagnosis}

Data from the Swedish Cancer Registry and from regional cancer registries were used. Additionally, each participant was asked if she had any history of neoplastic disease and, if so, she was asked to provide details regarding the type, localization, and treatment of the disease. Information from the 32-year period from 1968-1969 to 2000-2001 was obtained. A previous comparison between the 1988 Cancer Registry and observations made in the Prospective Population Study of Women showed $99 \%$ agreement. ${ }^{14}$

During the follow-up period, data on mortality were obtained from the population registry and the Cause of Death Register. Women's death certificates were analyzed; if the cause of death was not clear, additional data were gathered from hospital and medical records.

\section{Results}

\section{Causes of death in women}

The most commonly observed causes of death during the 32-year follow-up period are shown in Table 2 and in Figures 1 and 2. In the younger age group (born in 1918), which was followed until the age of 82 years, death from

Table 2 Causes of death for women followed from 50 to 82 years of age, and from 54 to 86 years of age, respectively

\begin{tabular}{|c|c|c|c|c|}
\hline & \multicolumn{2}{|c|}{$\begin{array}{l}\text { From } 50 \text { to } \\
82 \text { years of age }\end{array}$} & \multicolumn{2}{|c|}{$\begin{array}{l}\text { From } 54 \text { to } \\
86 \text { years of age }\end{array}$} \\
\hline & $\mathbf{n}$ & $\%$ & $\mathbf{n}$ & $\%$ \\
\hline Myocardial infarction & 27 & 16 & 29 & 25 \\
\hline Other cardiovascular diseases & 15 & 9 & 15 & 13 \\
\hline Stroke & 20 & 12 & 16 & 14 \\
\hline Cancer & 52 & 31 & 28 & 24 \\
\hline Other reason & 52 & 31 & 27 & 23 \\
\hline Total & 166 & & 115 & \\
\hline
\end{tabular}

Abbreviation: $n$, number of participants. 


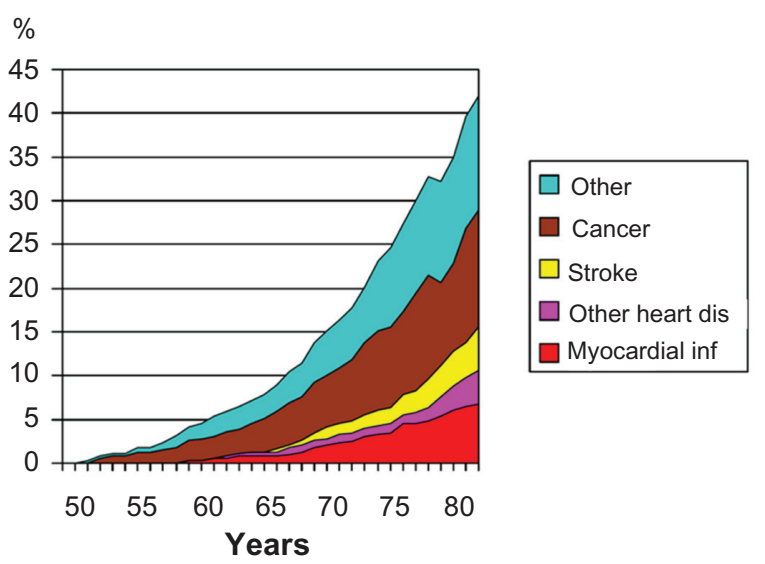

Figure I Causes of death in women born in 1918, followed from 50 to 82 years of age (total of 32 years).

cancer was twice as common as death from myocardial infarction, while in the older age group (born in 1914), which was followed until the age of 86 years, death from myocardial infarction was as common as death from cancer. Figures 1 and 2 show the cumulative frequency of causes of death in both age groups. Stroke was a common cause of death at younger ages and accounted for nearly $15 \%$ of deaths.

In an examination of causes of death between ages 60-80 years (Figures 1 and 2), the results were approximately the same in both age cohorts; the percentage of deaths from cancer was $30 \%$ of deaths, from myocardial infarction $19 \%$, and from stroke $14 \%$. Of women who died between $80-85$ years of age, $34 \%$ had been diagnosed with fatal myocardial infarction, $15 \%$ suffered from cancer, and $12 \%$ suffered from stroke. After 80 years of age, myocardial infarction appeared to be a more frequent cause of death than cancer.

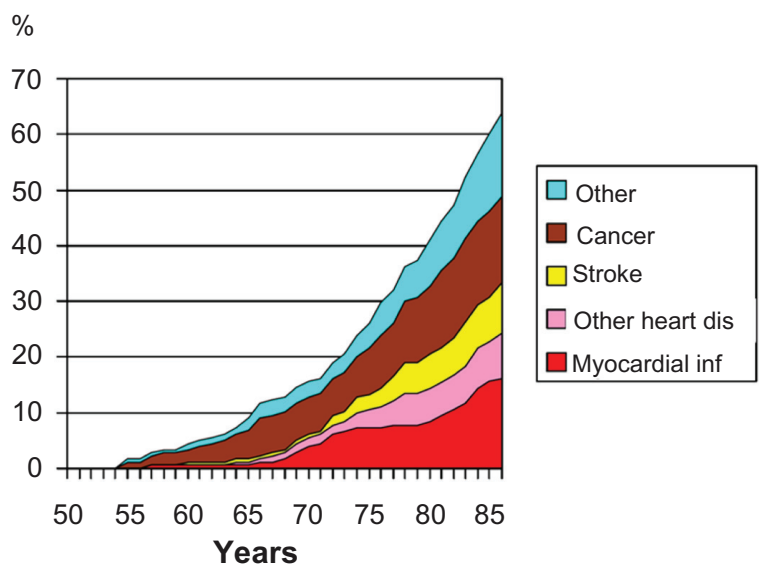

Figure 2 Causes of death in women born in 1914, followed from 54 to 86 years of age (total of 32 years).

\section{Discussion}

Our study presents mortality and causes of death in two representative birth cohorts examined in the Population Study of Women in Gothenburg, Sweden, which were followed for 32 years. Cancer was a more common cause of death than both myocardial infarction and stroke in women aged between 60-80 years. Similar observations were made in Iceland. ${ }^{15}$ In women aged between 55-85 years, cancer and ischemic heart disease caused $40 \%$ and $11 \%$ of deaths in Iceland in 2007 , respectively. Data regarding myocardial infarctions in Gothenburg in the late 1960s and early 1970s for men and women aged 67 years and younger ${ }^{16}$ revealed that myocardial infarction was six to eight times more common in men than in women of the same ages. ${ }^{17}$ Although this difference has decreased, men continue to experience significantly higher morbidity and mortality from myocardial infarction than do women. ${ }^{18}$ The incidence of myocardial infarction increases with increasing age; some studies have shown that patient age was more important than patient sex in the rate of myocardial infarction. ${ }^{19}$ Although myocardial infarction is less frequent in women than in men of younger ages, short-term outcomes are worse for women than for men. ${ }^{3}$ Thus, rapid diagnosis and clear support objective methods must be in place.

Stroke was found to be a common cause of death in women in our study. These findings agree with those of earlier reports. ${ }^{20,21}$ Stroke is one of the leading causes of death worldwide. ${ }^{22}$

Our study shows that it is important not only to focus on myocardial infarction and stroke, but to emphasize the risk of suffering from cancer in women younger than 80 years of age..$^{20,21}$ These observations are important for planning of preventive care such as cancer screening. It is important to identify and to motivate women who do not participate in screening programs against breast cancer and cervical cancer. Patients and health care providers should be aware of the importance of smoking cessation, sufficient physical activity, and maintaining a healthy weight in reducing the cancer burden. ${ }^{23}$

It is not meaningful to discuss which cause of women's causes of death is the most important. Cardiovascular disease is likely the most common overall cause of death in women, ${ }^{5-7,24}$ while cancer results in the highest number of lost years of life. Our results agree well with those presented by the Swedish National Board of Health and Welfare, which show that twice the number of life years were lost due to cancer compared to cardiovascular disease in women younger than 75 years old. ${ }^{25}$ Our results are in agreement with crosssectional national statistics data from Nordic countries, which 
show that cancer is the most common cause of premature death in those younger than 75 years old. ${ }^{26}$

Among the advantages of this study are the longitudinal design and the long follow-up period ranging from 1968-1969 to 2000-2001. Statistics regarding causes of death can be based on a national level, but in a limited, welldefined population, higher quality data can be obtained. Using record briefings, interviews, and surveys, more reliable diagnosis can be reported than use of a review of publicly collected data. The main limitation of the study is the limited number of women who were followed-up. However, the quality of the data exceeds the limitation of the small sample size.

\section{Key points}

It is important not only to focus on myocardial infarction as the main cause of death in women, but also to emphasize that the causes of death vary in relation to the ages of women. The risk of suffering from stroke in women examined in this study is significant, and the presence of cancer before 80 years of age is more common than both myocardial infarction and stroke. These observations are important for planning of care, prevention, and research in women's health.

\section{Ethical approval and participants consent}

The Ethics Committee of University of Gothenburg approved this study. All subjects gave informed consent, in accordance with the provisions of the Helsinki Declaration.

\section{Acknowledgments}

This study was supported by grants from the Swedish Council for Working Life and Social Research (2005-0794, 2007-1958) and the Bank of Sweden Tercentenary Foundation.

\section{Disclosure}

The authors declare no conflict of interest.

\section{References}

1. Poon S, Goodman SG, Yan RT, et al. Bridging the gender gap: Insights from a contemporary analysis of sex-related differences in the treatment and outcomes of patients with acute coronary syndromes. Am Heart J. 2012;163(1):66-73.

2. Mendelson MA, Hendel RC. Myocardial infarction in women. Cardiology. 1995;86(4):272-285.

3. Hanratty B, Lawlor DA, Robinson MB, Sapsford RJ, Greenwood D, Hall A. Sex differences in risk factors, treatment and mortality after acute myocardial infarction: an observational study. J Epidemiol Community Health. 2000;54(12):912-916.
4. American Heart Association [homepage on the Internet]. Dallas [cited April 6, 202] Available from: http://www.heart.org/HEARTORG/. Accessed April 6, 2012.

5. Department of Health and Human Services [homepage on the Internet]. Atlanta [cited April 6, 2012] Centers for disease control and prevention. Leading Causes of Death in Females United States, 2007. Available from: http://www.cdc.gov/women/lcod/. Accessed April 6, 2012.

6. World Health Organization [homepage on the Internet]. Switzerland. Women's Health Fact Sheet N³34 Nov 2009 [cited April 6, 202]. Available from: http://www.who.int/mediacentre/factsheets/fs334/en/ index.html. Accessed April 6, 2012.

7. The National Board of Health and Welfare Sweden. [homepage on the Internet]. Sweden. Causes of Death 2007 Socialstyrelsen 2009 [cited April 6, 2012]. Available from: http://www.socialstyrelsen.se/ publikationer2009/dodsorsaker2007. Accessed April 6, 2012.

8. Ezzati M, Friedman AB, Kulkarni SC, Murray CJ. The reversal of fortunes: trends in county mortality and cross-county mortality disparities in the United States. PLoS Med. 2008;5(4):e66.

9. Barford A, Dorling D, Davey Smith G, Shaw M. Life expectancy: women now on top everywhere. BMJ. 2006;332(7545):808.

10. Mathers CD, Boerma T, Ma Fat D. Global and regional causes of death. Br Med Bull. 2009;92:7-32.

11. Murray CJ, Lopez AD. Global mortality, disability, and the contribution of risk factors: Global Burden of Disease Study. Lancet. 1997;349(9063):1436-1442.

12. Bengtsson C, Blohme G, Hallberg L, et al. The study of women in Gothenburg 1968-1969 - a population study. General design, purpose and sampling results. Acta Med Scand. 1973;193(4):311-318.

13. National Center for Health Statistics (US). Commission on Professional and Hospital Activities. The International Classification of Diseases: 9th Revision, Clinical Modification: ICD-9-CM. 4th ed. Washington, DC: US Dept of Health and Human Services, Public Health Service, 1991.

14. Bengtsson C, Gredmark T, Hallberg L, et al. The population study of women in Gothenburg 1980-2012-the third phase of a longitudinal study. Comparison between participants and non-participants. Scand $J$ Soc Med. 1989;17(2):141-145.

15. Statistics Iceland. [homepage on the Internet]. Reykjavík. Births and deaths 2007 [cited April 6, 202]. Available from: http://www.statice/ is/Statistics/Population/Births-and-deaths. Accessed April 6, 2012.

16. Elmfeldt D, Wilhelmsen L, Tibblin G, Vedin JA, Wilhelmsson CE, Bengtsson C. Registration of myocardial infarction in the city of Goteborg, Sweden. J Chronic Dis. 1975;28(3):173-186.

17. Bengtsson C. Ischaemic heart disease in women. A study based on a randomized population sample of women and women with myocardial infarction in Goteborg, Sweden. Acta Med Scand Suppl. 1973;549: $1-128$.

18. Bengtsson C. Myocardial infarction among women. Is it possible to prevent? Lakartidningen. 1994;91(48):4483-4484.

19. Fransoo RR, Martens PJ, Prior HJ, Burland E, Chateau D, Katz A. Age difference explains gender difference in cardiac intervention rates after acute myocardial infarction. Healthc Policy. 2010;6(1):88-103.

20. Liebetrau M, Steen B, Skoog I. Stroke in 85-year-olds: prevalence, incidence, risk factors, and relation to mortality and dementia. Stroke. 2003;34(11):2617-2622.

21. Andersson M, Guo X, Borjesson-Hanson A, Liebetrau M, Ostling S, Skoog I. A population-based study on dementia and stroke in 97 year olds. Age Ageing. Epub March 19, 2012.

22. Ingall T. Stroke - incidence, mortality, morbidity and risk. J Insur Med. 2004;36(2):143-152.

23. Underwood JM, Townsend JS, Stewart SL, et al. Surveillance of demographic characteristics and health behaviors among adult cancer survivors-Behavioral Risk Factor Surveillance System, United States, 2009. MMWR Surveill Summ. 20 2012;61(1):1-23.

24. Lawton JS. Sex and gender differences in coronary artery disease. Semin Thorac Cardiovasc Surg. 2011;23(2):126-130. 
25. The National Board of Health and Welfare Sweden [homepage on the Internet]. Sweden. Folkhälsorapport. 2005. Socialstyrelsen 2005 [cited April 6, 2012]. Available from: http://www.socialstyrelsen.se/ publikationer2009/2009-2126-71. Accessed April 6, 2012.
26. Sigurdsson JA, Getz L, Vainiomäki P, Sjonell G, Brodersen J. Marginal public health gain of screening for colorectal cancer: modelling study, based on WHO and national databases in the Nordic countries. $J$ Eval Clin Pract. April 12, 2012. [Epub before print.]

\section{Publish your work in this journal}

The International Journal of General Medicine is an international, peer-reviewed open-access journal that focuses on general and internal medicine, pathogenesis, epidemiology, diagnosis, monitoring and treatment protocols. The journal is characterized by the rapid reporting of reviews, original research and clinical studies across all disease areas.
A key focus is the elucidation of disease processes and management protocols resulting in improved outcomes for the patient.The manuscript management system is completely online and includes a very quick and fair peer-review system. Visit http://www.dovepress.com/ testimonials.php to read real quotes from published authors.

Submit your manuscript here: http://www.dovepress.com/international-journal-of-general-medicine-journal 